\title{
Componential Theories of Creativity: A CaSe Study of Teaching Creative PROBLEM SOLVING
}

\author{
Chris Rennick and Kenneth N. McKay \\ University of Waterloo \\ crennick@uwaterloo.ca and kmckay@uwaterloo.ca
}

\begin{abstract}
Engineering is the discipline of applying scientific and mathematical tools to solve practical problems for society. At the core of a person's problemsolving abilities is their creativity. This is a preliminary and exploratory theory-based paper summarizing the two most prevalent componential theories of creativity as applied to a case study. These theories outline a set of processes which contribute to a person's ability to be creative in a domain. The components differ slightly between models, but include: motivation; domainspecific knowledge, skills, and abilities; and cognitive process of creativity including problem finding, ideation, and evaluation.
\end{abstract}

To demonstrate the practical application of these theories to engineering pedagogy, they will be applied to a case study of a 2-day academic hackathon called "Tron Days". Tron Days guides students through a multi-step modelling and verification process and concludes with teams of students designing and constructing a robotic arm. At the end of the second day, students demonstrated their functioning robotic prototypes. This event has now been run twice for first semester Mechatronics Engineering students, and similar implementations with different problems have been run in seven other engineering programs at the same institution. Each section of this paper will demonstrate the application of componential theories of creativity by drawing connections to the Tron Days event.

Keywords: creativity, problem solving, cognitive theories, case study

\section{INTRODUCTION}

Different definitions of creativity abound and often creativity is not crisply defined [1]. Sternberg and Lubart's [2] definition is representative of most other definitions: "Creativity is the ability to produce work that is both novel (i.e. original, unexpected) and appropriate (i.e. useful)." Many researchers have added to these fundamental criteria of novelty and usefulness in different ways: Kaufman and Sternberg [3] require that creative ideas must be of high quality, MacKinnon [4]

CEEA18; Paper 45

University of British Columbia, June 3-6, 2018 Page 1 of 10 emphasized that the original insight must be elaborated upon (i.e. the idea must be fully developed), Moran [5] included problem formulation as part of creativity.

In the engineering context, Cropley and Cropley [6] use the term functional creativity to emphasize that a solution can't be just novel, or aesthetic, but must be useful. Charyton and Merrill's [7], and Harris' [8] tests for creativity in engineering reinforce this point: their tests rely extensively on "alternate uses"-type tests which require the test-taker to come up with new, useful applications for a presented object or shape.

The working definition of creativity used in this paper is that of Kaufman and Sternberg [3]: creative ideas must be new, of high quality, and appropriate to the task at hand. This definition is used as it is comprehensive and approachable to engineers (who are used to assessing quality and appropriateness).

Since Guilford's 1950 Address of the President of the American Psychological Association [9], research into creativity has expanded rapidly. To capture the broad spectrum of creativity, dozens of theories have been proposed with texts devoted to summarizing them [10] [11]. However, many of these theories are difficult to apply to the Engineering Education context.

\subsection{Creativity in Engineering}

Problem solving lies at the core of the engineering discipline. Fogler and LeBlanc [12] in their problemsolving heuristic (which is representative of many problem-solving heuristics, the engineering design cycle included) define five steps to solving a problem: define the problem, generate solutions, decide a course of action, implement a solution, and evaluate the solution. Most people would agree that creativity is needed when generating solutions, however one could argue that it is necessary throughout the process. For example, when implementing a solution, an engineer needs to identify all possible ways in which the solution could be implemented and choose one. This could require creative applications of existing technologies, new uses for materials or manufacturing processes, or borrowing strategies from other fields. If problem solving is at the 
core of Engineering, then creativity could be viewed as the core of problem solving.

Speaking more generally about the engineering discipline, Florida [13] defined the "creative class" of workers as those people working in "jobs in knowledgeintensive industries that involve the production of new ideas and products, or that engage in creative problem solving". In his classification of occupations which belong to the "creative class", Florida not only included engineers, but the closely related designers, architects, and computer scientists.

Creativity is also important to engineers: Neufeld et al [14] found that engineers and engineering students value creativity, that creativity is generally a positive behavior, and $92 \%$ of respondents from the College of Engineering felt they were creative at least some of the time.

While neither of the two accrediting bodies for engineering programs in North America: the American Accreditation Board for Engineering and Technology (ABET) [15] and the Canadian Engineering Accreditation Board (CEAB) [16] explicitly list creativity as a student outcome, they each list several outcomes which rely on creativity.

\subsection{Purpose of Study}

Given the importance (and prevalence) of creativity to engineering, instructors should be spending effort to better train their students to be creative. Scott et al. [17] in their review of existing creativity training emphasize the importance of having a clear cognitive model in mind when designing new creativity training programs. They identified four features of successful creativity training:

1) The training is based on sound, valid conception of the cognitive activities underlying creativity

2) The training should be lengthy, relatively challenging, and focus on discrete cognitive skills

3) Articulation of creativity principles should be followed by applications on "real world" problems

4) Presentation of the material should be followed by a series of exercises appropriate to the domain At the University of Waterloo, the Engineering Ideas Clinic has been developing challenging, real-world activities where students are given a structured opportunity to be creative for several years. Since 2016, these activities have largely taken the form of Engineering Design Days events (see [18] for a full description). These events have been designed based on extensive instructor experience as well as the principles of High-Impact Practices [19], but were not designed with a clear cognitive model of creativity. A cognitive model needed to be identified for two reasons:
- to better align with best practices in creativity training as outlined by Scott et al [17],

- to distill the experience of the founding Ideas Clinic instructors for new people joining the initiative

This paper presents the results of this search: a pair of componential theories of creativity which are useful to the educational context were identified. For this paper, these theories have been applied to the Mechatronics version of Engineering Design Days, called "Tron Days" to demonstrate how these models apply to Engineering pedagogy. Each section of this paper will conclude with a case study application of the preceding theory.

\subsection{Case Study: Tron Days}

Engineering Design Days were piloted in 2015 and are characterized by multi-day, immersive design challenges where students work in teams to design and build solutions to discipline-specific problems. As of this writing, Engineering Design Days activities have been run in eight different engineering programs to great success (see [20] and [21] for descriptions of some of these events). The course-level learning outcomes have been largely achieved and the students have been enthusiastic about engaging.

Tron Days is the Engineering Design Days activity for first semester Mechatronics Engineering students and was offered in both 2016 and 2017. All lectures, labs, and tutorials were rescheduled for 2 days to provide time for this activity. For clarity, this paper will limit the discussion to the fall 2017 offering of the activity; see Li et al. [22] for a discussion of the 2016 offering.

The challenge in 2017 was for students to design a tele-operated robotic arm which could lift small 3D printed shapes and place them in specific locations on a vertical wall. In the morning of the first day, students were guided through a scaffolded set of warm-up problems. Upon completion of the final warm-up problem, the students were handed Tetrix Prime kits [23] and pneumatic components and began construction of their arms. The afternoon of the second day was devoted to demonstrations and functional testing. Following the event, students reflected on their experiences with a written assignment. The event was mandatory, and assessments were strategically placed throughout the event to allow the teaching team to monitor student progress. These assessments focused on the students' process, not their final product.

\section{THEORIES OF CREATIVITY}

Kozbelt, Beghetto, and Runco [11] in their review of the various theories of creativity identified 10 broad categories: Developmental, Psychometric, Economic, 
Stage/Componential Process, Cognitive, ProblemSolving/Expertise-Based, Problem Finding, Evolutionary (Darwinian), Typological, and Systems. Not all of these theories are useful to an undergraduate educational context. Componential theories, however, with their identification of the cognitive processes that contribute to creativity, show great potential for designing effective training programs in Engineering.

\subsection{Componential Theories of Creativity}

Amabile proposed a componential model for creativity in 1983, which was updated in 1996 [24]. This model has three components: task motivation, domain-relevant skills, and creativity-relevant processes. Task motivation reflects a person's reasons for working on a task, which includes interactions of intrinsic and extrinsic motivation. Domain-relevant skills are a person's knowledge about the task, their skills, and their talents. Creativity-relevant processes include cognitive skills related to the task (including problem solving heuristics and strategies), as well as personal qualities like persistence and sustained attention. This model also includes five phases of the creative process, which don't necessarily occur in this order, and which may occur more than once: 1) problem or task identification, 2) preparation, 3) response generation, 4) response validation and communication, and 5) Outcome [25]. Figure 1 below summarizes the interactions between the different components of the model.

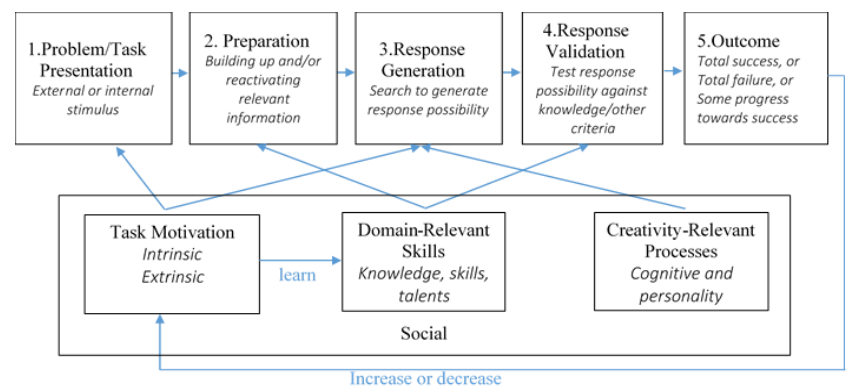

Figure 1 Componential framework of creativity. [24]

Different components are required in varying quantities during different phases of the creative process (e.g. intrinsic motivation is very important to the problem identification phase whereas extrinsic motivation can be useful in the response validation phase) [25]. In addition, the components of this model are multiplicative: creativity is highest when an intrinsically motivated person with high domain expertise and high skill in creative thinking works in an environment high in supports for creativity.

A second model was proposed by Runco and Chand [26]. This model relies on many of the same components as found in Amabile's model, but with slightly different

CEEA18; Paper 45

University of British Columbia, June 3-6, 2018 Page 3 of 10 language and organization. Runco and Chand's model includes a primary tier of creative processes which includes problem finding, ideation, and evaluation processes. They structure their model with a secondary tier of knowledge and motivation, as in their view "they are contributing rather than controlling factors, and in many ways they are dependent on the primary factors" [26]. Figure 2 below summarizes this model.

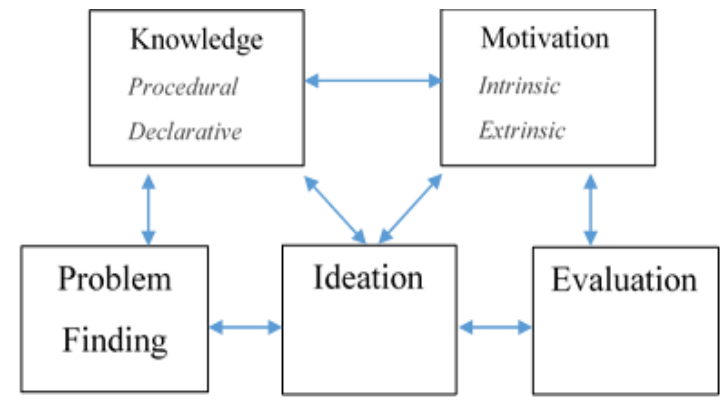

Figure 2 Two tier model of creative thinking [26].

While these are not the only componential theories of creativity - Baer and Kaufman, for example, have their Amusement Park Theoretical Model of Creativity [27] the two presented theories show promise as a theoretical underpinning for creativity training in Engineering.

\subsection{Case Study: Tron Days}

Amabile's componential framework includes five steps in the creative process: problem presentation, preparation, response generation, response validation, and outcome. Tron Days was designed for students to proceed through this process twice: once in the warm-up problems (where little creativity is possible), and again during the main design (where creativity is encouraged).

The problem presentation begins before the event with careful messaging in class: Tron Days will present a real engineering problem, and students will gain skills that will aid them on their first work terms (which happens immediately after this semester for half of the students). These messages are designed to stir intrinsic motivation (the students will get to experience engineering), and extrinsic motivation (this event will help them find their first co-op job). The problem description are not released to students until the start of the event (see Appendix A for a full problem set).

Since the students have only been attending university for 5 weeks when they take part in Tron Days, the warmup problems are heavily constrained. Each warm-up problem was designed to draw on knowledge from a specific course the students are enrolled in that semester (chemistry, calculus, algebra, programming, and engineering graphics). For the large design problem, the warm-up problems prepare students through the 
construction of the different mathematical/computer models of the robotic arm.

Response generation is required for the students to develop a solution to the large design problem. Tron Days had an award for "thinking outside the box/taking the biggest risk" which was meant as an extrinsic motivator for students to push themselves to develop creative solutions to the assigned problem.

Response validation for the warmup problems occurs naturally as they progressed through the problems: their $\mathrm{C}++$ program validates their mathematical modelling, and their AutoCAD model validates their $\mathrm{C}++$ program. For the large design problem, the students had access to the scoring rubric for the event and had access to a number of test stations to validate their design throughout the build process. The final test came at the end of the second day when they demonstrated their design to a course Teaching Assistant.

\section{COMPONENTS}

\subsection{Problem Finding}

Not all problems require clear and explicit creativity to solve, however many of the situations faced by engineers are ill-defined with conflicting goals (e.g. something can be cheap, fast, or reliable, pick two) which do require a form of creativity and problem-solving to resolve. Getzels [28] provides a helpful taxonomy of the types of problems which one may face:

1. Presented problem situation: a problem is given to the solver. This problem has a known formulation, or a known method of solution.

2. Discovered problem situation: a problem exists and is discovered by the solver. There may not be known methods of solutions, or solutions.

3. Created problem situation: a problem does not exist at all until someone invents or creates it (e.g. an educator crafting an exam question).

In discovered and created problem situations, it is not possible to jump immediately to a solution, the problem needs to be better understood first. Mumford et al, stated this as follows: "people must begin creative problemsolving efforts by imposing structure on the ill-defined situation - identifying the nature of the problem at hand and the kind of goals, procedures and information that should be considered later in problem-solving activities." [29]. The process of imposing structure, drawing problem representations/analogies from previous work, collecting additional information, etc. describes problem finding, which is sometimes referred to as problem construction or problem identification.
A number of studies have been performed looking at the impacts of problem finding on creativity (see [26] [30] [31] [32]). Chand and Runco [33] summarizing prior work in the field concluded that "problem finding is... an important and distinct component of the creative process, and can be reliably assessed." In the context of education, Runco and Okuda [30] suggest providing students with tasks that are extremely open-ended, to allow students to discover problems, and provide them a place to practice their problem discovery and identification skills.

3.1.1 Case Study: Tron Days. Tron Days began with a presented problem situation: the teaching team created a simplified design of a robotic arm that was limited to two degrees of freedom. Warm-up problems with simplified systems were presented to students to allow them to explore the problem space. This early work was critical for students to practice their domain-relevant knowledge. Once the students completed these starting problems, they transitioned to designing their own robotic system. To design their systems, the students were forced to study the challenge, examine the shortcomings of the simplified system from the starting problems, and determine improvements. The students needed to explore the problem and the components they were given and seek out any missing information so they could begin brainstorming alternative designs.

During the event, some flaws in the implementation were observed. Anecdotally, the teaching team noticed that too little time was set aside for the problem finding process. Students were keen to start building and were not given sufficient time to work through the starting problems and reflect on what had been learned. In many cases students who were struggling to solve the starting problems set them aside, and just started building. Additionally, in the comments collected from students there was evidence of confusion in the transition from scaffolded problems to the openness of the final design. Many of the students commented that it was unclear whether they had to keep elements of the warm-up design, or if they were allowed to start from scratch.

In future offerings of the activity, the starting problems will be given to students in advance of the event as an assignment. This will allow them to spend time to develop an understanding of the problem space. This change should also improve the clarity around when creativity is expected from students. This will also provide additional time during the event to explore the shortcomings of the arm design from the warm-up problems and of the equipment they will be building with, think up creative solutions, and evaluate their designs before construction starts. 


\subsection{Ideation}

Ideation, or more commonly, divergent thinking, is one of the most studied components to human creativity. To quote Runco [34]: "Divergent thinking is really just what the name implies, a cognitive process that leads in divergent directions."

Many of the clinical creativity tests only examine divergent thinking. These tests take many forms, but they are typically scored for 4 criteria: fluency, flexibility, originality, and elaboration of ideas [35]. The most commonly employed Divergent Thinking (DT) tests are the TTCT (Torrance Tests for Creative Thinking) [36]. There is widespread support for the validity of divergent thinking tests [34] and for their predictive capability for future creative achievement [37], though there are some debates surrounding their use.

Care needs to be taken with the application of divergent thinking test batteries and the generalizability of the results they produce: divergent thinking is often seen as being synonymous with creativity, which is not the case (see Runco [34]) There is, however, no doubt to the importance of divergent thinking skills to a person's creativity [36].

3.2.1 Case Study: Tron Days. A problem needs to be open-ended with no "correct answer" for divergent thinking to be required and useful. The challenge in Tron Days, while carefully structured and controlled in scope, gives students the freedom to implement their own solution.

During Tron Days, the creativity demonstrated in students' solutions makes clear that they had engaged in divergent thinking. Either driven by a need to be the best, to be different from their peers, or because the challenge had no "right answer", even when given the same equipment, no two solutions were the same. It should be noted that there was an award for the student team who either "took the biggest risk" or for "thinking outside of the box", which may also have motivated them to develop a solution different from their peers.

Future iterations of the event will be structured slightly differently to allow additional time for students to evaluate alternative designs and select one. No building materials will be provided on day 1 to ensure that proper attention is given to the design of their robotic arm before construction begins.

\subsection{Evaluation}

Runco and Chand [26] summarized evaluative processes as falling in three major categories:

1. evaluation (critical) and valuation (appreciative), CEEA18; Paper 45

University of British Columbia, June 3-6, 2018 Page 5 of 10
2. intrapersonal and interpersonal evaluations, and

3. evaluative skills using originality and creativity as criteria versus correctness.

Unfortunately, evaluation receives little attention in the literature on creativity. For example, the Cambridge Handbook of Creativity [38] has no mention of "evaluation", "valuation", nor the more common phrase "convergent thinking", and the Handbook of Creativity [39] devotes only 2 pages to the relationship between convergent and divergent thinking; and yet processes relating to evaluation appear in Amabile's model in the Response Validation and Outcome phases, and more explicitly in Runco and Chand's model in the primary tier of processes. Runco, in [34] speaks to the importance of evaluation to creativity: "without some sort of evaluation, divergent thinking might lead to high originality that lacks fit and effectiveness."

Runco [40] describes the relationship between convergent thinking and divergent thinking as follows: "creative thinking requires that a person first generate options using divergent thinking skills and then select the best idea or ideas from that set of options using critical thinking skills".

Valuation, like evaluation, ultimately ends with the selection of one possibility, however the criteria of selection are different. Evaluation achieves selection through critical thinking, whereas valuation achieves selection based on other criteria (e.g. most original). Using valuative methods can provide clarity to the useful aspects of an original suggestion.

Revision may also play an important role in producing a creative work. One needs to be careful to differentiate high quality from highly creative, however Hayes [41] emphasizes the importance of revision to creativity.

Evaluation processes are crucial to problem-solving in the engineering context. A proposed solution needs to be evaluated for correctness, feasibility, legality, cost, robustness, manufacturability, impact on the environment, etc. before it can be approved. This component of creativity relies on domain-specific knowledge, is well understood by engineers, and is already present throughout engineering curricula.

3.3.1 Case Study: Tron Days. As mentioned previously, the warm-up problems were structured to validate previous problems in the sequence. The first 2 problems were analytical problems to get the students to work through the robotic arm geometry on paper. The programming problem which followed could be used to validate their hand calculations. This problem also required them to evaluate the hardware they would be using to determine minimum, maximum, and increment values for the four variables in the program. They also 
had to evaluate the demonstration setup to determine a "useful" range of outputs for the program. Lastly, the students had to take the output of their program (which typically produced around 10 useful arm configurations), select one, and draw that configuration in AutoCAD. This drawing could then be used to validate that their program was performing the calculations correctly.

During the design and construction of their robotic arms students had to be constantly checking that their proposed solution was capable of performing the presented challenge. This required them to evaluate the strength, speed, and capabilities of their robotic arm and then iterate on their solution where shortcomings were identified. While evaluation was heavily emphasized in the event, those who were striving for the creativity awards would have also been valuating their design with creativity as the criterion.

\subsection{Knowledge}

Runco and Chand's two-tier model of creative thinking distinguishes between declarative and procedural knowledge. Declarative knowledge is factual information, which in an academic setting is largely obtained through coursework. Procedural knowledge represents know-how, or strategies for creative thinking [26]. Heuristics like TRIZ [42], the engineering design cycle, and other similar strategies [12] are forms of procedural knowledge. As people move through day to day life building experience, they will develop their own procedural knowledge of methods that worked, or that didn't work, when solving problems. These procedures can become routine over many years leading to lower flexibility of solutions, and therefore lower creative output. Many published methods for improving one's creativity are different procedures for developing ideas (e.g. de Bono's Six Thinking Hats [43]).

The impact of declarative knowledge on creativity is much more obvious: for one to be creative in a field, they must have sufficient understanding of the field. Thinking back to the definitions of creativity, for something to be creative it needs to be useful. Without expertise in, and knowledge of, the problem space, it would be exceedingly difficult to develop something useful. Hayes [41] provides a number of mechanisms which could explain why experts have a higher capacity for creativity.

There have been many studies looking at the impact of expertise on creativity. Hayes in a study of eminent composers and their master-works found that only 3 were composed before year 10 of their career [41]. This " 10 year rule" is consistent across many domains and is consistent with views on expertise acquisition [44] [45].

CEEA18; Paper 45

University of British Columbia, June 3-6, 2018 Page 6 of 10
Amabile [24] presents a more holistic knowledge component than Runco and Chand. The "Domainrelevant skills" component of her model includes knowledge about the domain (as with Runco and Chand's model), but also includes required technical skills, and domain-relevant talents. Technical skills could be perceptual, motor, laboratory, construction, or other skills. Talents are anything that an individual has a natural aptitude for. Amabile goes on to explain that it is not only the possession of knowledge, but how its organized: "knowledge organized according to general principles will be of greater utility than specific, narrowly applicable collections of facts." [24] Therefore, participating in any activity that helps to integrate individual facts into a larger picture should have positive impacts on a person's creativity.

3.4.1 Case Study: Tron Days. Tron Days' six learning outcomes focus on knowledge/skill acquisition and application. The main objective of the event is to learn, not to demonstrate mastery: Tron Days was conceived and implemented as a formative activity for students in their first academic semester. As such, there is little evaluation of the end product. There is instead a focus on evaluating the students' communication of their design process.

The warm-up problems were designed to simulate an engineer's work process and require students to integrate knowledge from all 5 of their courses. The problems were constructed to build on one another and to validate prior steps in the process. Because Tron Days was designed for first year students, these warm-up problems have less ambiguity: students are presented with a representation that they can immediately work with to solve the problems. Tron Days, therefore, guides students through the stages in Amabile's model with the most reliance on domain-relevant skills: problem/task presentation, preparation, and validation before opening up the problem for the final arm design.

As the students work in teams of 4 , and are presented with 4 warm-up problems, they are naturally inclined to break up these problems and assign one to each group member. This obviously breaks the designed progression from pen and paper mathematical model to computer model to solid model, so attention needs to be paid during the event to control this behaviour.

\subsection{Motivation}

Much of the research between motivation and creativity has been carried out by Amabile since the 1970's. Her Intrinsic Motivation Hypothesis has undergone change over that time as the body of research has grown and has become the Intrinsic Motivation Principle (IMP): "Intrinsic motivation is conducive to 
creativity; controlling extrinsic motivation is detrimental to creativity; but informational or enabling extrinsic motivation can be conducive, particularly if initial levels of intrinsic motivation are high" [46].

There is significant empirical evidence that intrinsic motivation is beneficial to creativity. This evidence comes from clinical studies, case studies of eminent creators, and longitudinal studies [46]. There is also significant evidence that a match between the skills and talents of the creator and the task produces more creative solutions [26].

The second component of the IMP concerns "controlling extrinsic" motivation. These "controlling extrinsic" motives (like evaluation, external observation, and even rewards) are incompatible with intrinsic motives. There have been many studies examining the impact of various extrinsic motivators on creativity. The expectation of your work being assessed, being observed while completing a task, rules which control your behaviour while completing a task, and competing for prizes have all been shown to reduce creativity [46]. Amabile has suggested extrinsic motives could be dividing people's attention between the task at hand and the extrinsic goal [46].

The final component of the IMP concerns information or enabling extrinsic motivation. Collins and Amabile [46] describe the motivation-work cycle match as a possible mechanism to explain this:

At other points ... however, when the greater emphasis is on persistence or evaluation, synergistic extrinsic motivators may play a more important role... [they] may keep creators involved in a problem through times when they must acquire the skills and information necessary... Also... [they] may help creators to appropriately validate and communicate the solution to the field.

3.5.1 Case Study: Tron Days. The first component of Amabile's IMP [46], is that intrinsic motivation is conducive to creativity. Anecdotally, the first year Mechatronics Engineering students have always been a very keen, engaged group. The University of Waterloo attracts very driven, high-achieving students who enter their chosen discipline immediately upon admission. At UWaterloo, students need to find their first co-op position after 4-8 months of school, and so are very driven to participate in academic events that are perceived to help them find their first jobs. Tron Days, with its emphasis on engineering knowledge, hands-on skills, and professional skill development, can be very beneficial in this pursuit.

The second component of the IMP is that controlling extrinsic motivation is detrimental. The main controlling mechanism that instructors possess are course grades. To CEEA18; Paper 45

University of British Columbia, June 3-6, 2018 Page 7 of 10 limit the negative impact of grades to student creativity during Tron Days, grades have been kept to a minimum for the event. For Tron Days, the entire event is only worth $5 \%$ of the course grade in MTE 100, and is worth one assignment equivalent in their first semester programming course (about $1 \%$ of the course grade). In addition, only the final demonstration and presentation of their design (3/20 marks) is based on the performance of their prototype.

Lastly, informational or enabling extrinsic motivation can be conducive to creativity. Tron Days was designed with checkpoints spread throughout the first day to ensure students continue to make progress on their design. In future offerings, additional constructive feedback will be given on students' designs in the first day to increase learning and maintain motivation.

Tron Days also had 4 awards, one of which is awarded at the end of the first day to maintain excitement. Though the prizes are typically just a box of cookies, and so have little actual "value", these awards have been useful for engaging different elements of the class.

\section{DISCUSSION}

In the search for theories of creativity to underpin the work of the Ideas Clinic, Runco and Chand's model stood out as an easy to understand, but comprehensive theory. The components it presents are straightforward and align closely with existing Ideas Clinic activities: this model seemed to represent the collective experience of the founding Ideas Clinic instructors.

Amabile's model stood out due to the similarity between the process of creativity it presents, and processes like the engineering design cycle. When digging a little deeper, Amabile's model also includes a number of important factors that are left out of Runco and Chand's, including the effect of environment on creativity, and the addition of domain-specific skills and talents to the knowledge required to be creative. While these two theories are not perfect - this paper moved back and forth between them in the case study, as neither fully captured "creative problem-solving" in Engineering - they are both useful in their own ways.

These theories have already proven useful as a lens to examine the design of existing Ideas Clinic activities. Examining Tron Days through these theories illuminated issues in the ideation phase of the design process, for example. In future offerings, more time will be allocated to this phase and students will not be given any construction materials until the second day as a way of slowing down their design process and alleviating some of the competitive pressures the event can generate. 
The teaching team received a number of comments from students after Tron Days that the warm-up problems constrained their thinking as they were unsure whether their physical prototype had to match the results of the early analysis or not. In future offerings of Tron Days, it will be made clearer to students that they are not constructing the system presented in the warm-up problems, but instead an improved/expanded design of their own. Again, these theories aid in understanding the core problem students are complaining about: they were intrinsically motivated to design a creative solution but the instructions were constraining them during response generation.

For the design of future activities - especially with instructors with limited experience in training students' creative problem-solving skills - Runco and Chand's model can easily act as a sort of checklist: are each of the five components present? Is too much time given to one over the others? Are grades needed as extrinsic motivation to get students to push to the finish?

Many instructors when implementing a project have a tendency to overly constrain the problem. While careful control of the scope of the project is critical, too narrowly defining the problem removes any student practice of their problem finding skills. In other cases, an instructor may have students practice "being creative", but these activities tend to lack the evaluation component that is so critical in the engineering context. While an instructor may not want students to practice all 3 components in every activity, if you expect them to use these skills together in a capstone project and upon graduation, they need practice engaging in problem finding, ideation, and evaluation together in the same activity earlier in their academic careers.

\section{CONCLUSION}

Creativity (defined as something new, useful, and of high quality) is central to the problem-solving skills that engineers use on a day to day basis. Since the modern inquiry into creativity began, there have been many theories that seek to explain how creativity manifests in people, processes, places, and products. Of these many theories, componential theories of creativity show great promise to underpin the development of creative problem-solving pedagogy. Two componential theories were presented, consisting of the following components: knowledge/skills, motivation, problem finding, ideation, and evaluation.

The case study of Tron Days in this paper presented an academic event in an engineering context which engages all of the cognitive skills presented by the two componential theories of creativity described in this paper. The two presented componential theories of

CEEA18; Paper 45

University of British Columbia, June 3-6, 2018 Page 8 of 10 creativity describe many of the cognitive skills required by students when solving an open-ended design challenge like Tron Days, and so provide a useful structure to underpin the design of future academic events targeting engineering students' creative problem-solving skills. The success of Tron Days shows it is possible to design and implement a high-impact, authentic activity for a large first-year class that engages a holistic set of components of creativity.

\section{REFERENCES}

[1] J. A. Plucker, R. A. Beghetto and G. T. Dow, "Why Isn't Creativity More Important to Educational Psychologists? Potentials, Pitfalls, and Future Directions in Creativity Research," Educational Psychologist, vol. 39, no. 2, pp. 83-96, 2004.

[2] R. J. Sternberg and T. I. Lubart, "The Concept of Creativity: Prospects and Paradigms," in Handbook of Creativity, Cambridge, Cambridge University Press, 1999, pp. 3-15.

[3] J. C. Kaufman and R. J. Sternberg, "Preface," in The Cambridge Handbook of Creativity, Cambridge, Cambridge University Press, 2010, pp. xiii-xiv.

[4] D. W. MacKinnon, "The Nature and Nurture of Creative Talent," American Psychologist, vol. 17, no. 7, pp. 484495, 1962.

[5] S. Moran, "The Roles of Creativity in Society," in The Cambridge Handbook of Creativity, New York, Cambridge University Press, 2010, pp. 74-90.

[6] D. Cropley and A. Cropley, "Functional Creativity: "Products" and the Generation of Effective Novelty," in The Cambridge Handbook of Creativity, Cambridge, Cambridge University Press, 2010, pp. 301-317.

[7] C. Charyton, R. J. Jagacinski, J. A. Merrill, W. Clifton and S. DeDios, "Assessing Creativity Specific to Engineering with the Revised Creative Engineering Design Assessment," Journal of Engineering Education, vol. 100, no. 4, pp. 778-799, 2011.

[8] D. Harris, "The development and validation of a test of creativity in engineering," Journal of Applied Psychology, vol. 44, no. 4, pp. 254-257, 1960.

[9] J. Guilford, "Creativity," The American Psychologist, vol. 5, no. 9, pp. 444-454, 1950.

[10] M. A. Runco, Creativity Theories and Themes: Research, Development and Practice, London, UK: Elsevier, Inc, 2014.

[11] A. Kozbelt, R. A. Beghetto and M. A. Runco, "Theories of Creativity," in Cambridge Handbook of Creativity, Cambridge, UK, Cambridge University Press, 2010, pp. 20-47.

[12] S. H. Fogler and S. E. LeBlanc, Strategies for Creative Problem Solving, 2nd Ed., Upper Saddle River, NJ: Pearson Education, 2008. 
[13] R. Florida, "The Creative Class and Economic Development," Economic Development Quarterly, vol. 28, no. 3, pp. 196-205, 2014.

[14] P. Neufeld, O. Mirzaei, M. A. Runco and S. Maw, "Creativity in Design Engineers: Attitudes, Opinions and Potentially Influential Factors," in Canadian Engineering Education Association Conference, Halifax, NS, 2016.

[15] Accreditation Board for Engineering and Technology, "Criteria for Accrediting Engineering Programs," 20162017. [Online]. Available: http://www.abet.org/. [Accessed 6 December 2017].

[16] Engineers Canada, "Engineers Canada Consultation Group on Engineering Instruction and Accreditation Graduate Attributes," 7 January 2016. [Online]. Available: https://engineerscanada.ca/. [Accessed 6 December 2017].

[17] G. Scott, L. E. Leritz and M. D. Mumford, "The Effectiveness of Creativity Training: A Quantitative Review," Creativity Research Journal, vol. 16, no. 4, pp. 361-388, 2004.

[18] C. Rennick, C. Hulls, D. Wright, A. J. Milne, E. Li and S. Bedi, "Engineering Design Days: Engaging Students with Authentic Problem-Solving in an Academic Hackathon," in ASEE Annual Conference, Salt Lake City, UT, 2018 [submitted].

[19] G. Kuh, High-Impact Educational Practices: What They Are, Who Has Access to Them, and Why They Matter, Washington: AAC\&U, 2008.

[20] I. Ivkovic, T. L. Willett, M. J. Borland and M. Gorbet, "Design Days Boot Camp: Enhancing Student Motivation to Start Thinking in Engineering Design Terms in the First Year," in CEEA Annual Conference, Toronto, 2017.

[21] K. McKay, S. Mohamed and L. Stacey, "Concepts Only Please! Innovating a First Year Engineering Course," in CEEA Annual Conference, Halifax, 2016.

[22] E. Li, C. Rennick, C. Hulls, M. Cooper-Stachowsky, E. Boghaert, M. Robinson, W. Melek and S. Bedi, "Tron Days: Horizontal Integration and Authentic Learning," in CEEA Annual Conference, Toronto, 2017.

[23] Pitsco, "Tetrix Prime," 27 December 2017. [Online]. Available: https://www.tetrixrobotics.com.

[24] T. M. Amabile, Creativity in Context, Boulder, CO: Westview, 1996.

[25] T. I. Lubart, "Componential Models," in The Encyclopedia of Creativity, San Diego, CA, Academic Press, 1999, pp. 295-300.

[26] M. A. Runco and I. Chand, "Cognition and Creativity," Educational Psychology Review, vol. 7, no. 3, pp. 243267, 1995.

[27] J. Baer and J. C. Kaufman, "Bridging Generality and Specificity: The Amusement Park Theoretical (APT) Model of Creativity," Roeper Review, vol. 27, no. 3, pp. 158-163, 2005.

[28] J. Getzels, "Problem Finding: A Theoretical Note," Cognitive Science, vol. 3, no. 2, pp. 167-172, 1979.
[29] M. D. Mumford, W. A. Baughman, K. V. Threlfall, E. P. Supinski and D. P. Costanza, "Process-Based Measures of Creative Problem-Solving Skills: I. Problem Construction," Creativity Research Journal, vol. 9, no. 1, pp. 63-76, 1996.

[30] M. A. Runco and S. Okuda, "Problem discovery, divergent thinking, and the creative process," Journal of Youth and Adolescence, vol. 17, no. 3, pp. 211-220, 1988.

[31] S. Okuda, M. A. Runco and D. Berger, "Creativity and the Finding and Solving of Real-World Problems," Journal of Psychoeducational Assessment, vol. 9, no. 1, pp. 45-53, 1991.

[32] R. Reiter-Palmon, M. D. Mumford, J. O'Connor Boes and M. A. Runco, "Problem Construction and Creativity: The Role of Ability, Cue Consistency, and Active Processing," Creativity Research Journal, vol. 10, no. 1, pp. 9-23, 1997.

[33] I. Chand and M. A. Runco, "Problem finding skills as components in the creative process," Personality and Individual Differences, vol. 14, no. 1, pp. 155-162, 1993.

[34] M. A. Runco, "Commentary: Divergent Thinking is Not Synonymous With Creativity," Psychology of Aesthetics, Creativity and the Arts, vol. 2, no. 2, pp. 93-96, 2008.

[35] J. A. Plucker and M. C. Makel, "Assessment of Creativity," in The Cambridge Handbook of Creativity, Cambridge, UK, Cambridge University Press, 2010, pp. 48-73.

[36] M. A. Runco, G. Millar, S. Acar and B. Cramond, "Torrance Tests of Creative Thinking as Predictors of Personal and Public Achievement: A Fifty-Year FollowUp," Creativity Research Journal, vol. 22, no. 4, pp. 361368, 2010.

[37] M. A. Runco, G. Millar, S. Acar and B. Cramond, "Torrance Tests of Creative Thinking as Predictors of Personal and Public Achievement: A Fifty-Year FollowUp," Creativity Research Journal, vol. 22, no. 4, pp. 361368,2010 .

[38] J. C. Kaufman and R. J. Sternberg, The Cambridge Handbook of Creativity, Cambridge: Cambridge University Press, 2010.

[39] R. J. Sternberg, Handbook of Creativity, Cambridge: Cambridge University Press, 1999.

[40] M. A. Runco, "Critical Thinking," in Encyclopedia of Creativity, San Diego, CA, Academic Press, 1999, pp. 449-452.

[41] J. R. Hayes, "Cognitive Processes in Creativity," in Handbook of Creativity, Cambridge, UK, Cambridge University Press, 1989, pp. 135-145.

[42] G. Altshuller and L. Shulyak (translator), And Suddenly the Inventor Appeared TRIZ, the Theory of Inventive Problem Solving, Worcester, MA: Technical Innovation Center, Inc., 1996.

[43] The de Bono Group, LLC, "Six Thinking Hats," [Online]. Available: http://www.debonogroup.com/six_thinking_hats.php. [Accessed 13 January 2018]. 
[44] A. Kozbelt, "Longitudinal Hit Ratios of Classical Composers: Reconciling "Darwinian" and Expertise Acquisition Perspectives on Lifespan Creativity," Psychology of Aesthetics, Creativity, and the Arts, pp. 221-235, 2008.

[45] K. Ericsson and N. Charness, "Expert Performance," American Psychologist, pp. 725-747, 1994.

[46] M. A. Collins and T. M. Amabile, "Motivation and Creativity," in Handbook of Creativity, Cambridge, UK, Cambridge University Press, 1999, pp. 197-312.

\section{APPENDIX A - PROBLEM DESCRIPTIONS: TRON DAYS}
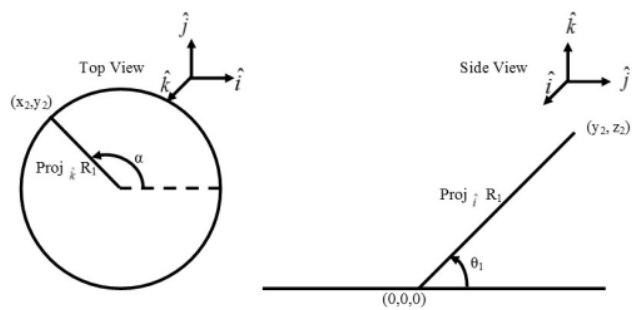

Figure A.1 Forward Kinematics Problem

A link $\mathrm{R}_{1}$ can be rotated by angle $\alpha$ (a roll about the $\mathrm{z}-$ axis) and raised/lowered by angle $\theta_{1}$ (a yaw about the $\mathrm{x}$ axis or $\hat{\imath}$ ). Give the vector equation that describes the location of the end effector: $R_{1}=x_{2} \hat{\imath}+y_{2} \hat{\jmath}+z_{2} \hat{k}$

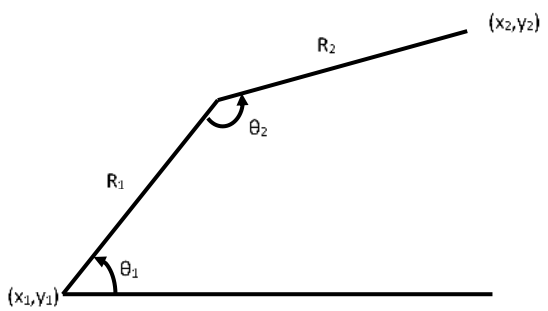

Figure A.2 Inverse Kinematics Problem

Given a starting location at $\left(\mathrm{X}_{1}, \mathrm{Y}_{1}\right)$ and two linkages of length $\mathrm{R}_{1}$ and $\mathrm{R}_{2}$, determine angles $\theta_{1}$ and $\theta_{2}$ such that the end effector at the end of $\mathrm{R}_{2}$ is located at $\left(\mathrm{X}_{2}, \mathrm{Y}_{2}\right)$. Represent this relationship such that for a given $\left(\mathrm{X}_{2}, \mathrm{Y}_{2}\right)$, you are able to produce a given $\theta_{1}$ and $\theta_{2}$ (i.e. $\theta_{1}=$ $\left.f\left(x_{2}, y_{2}\right), \theta_{2}=f\left(x_{2}, y_{2}\right)\right)$.

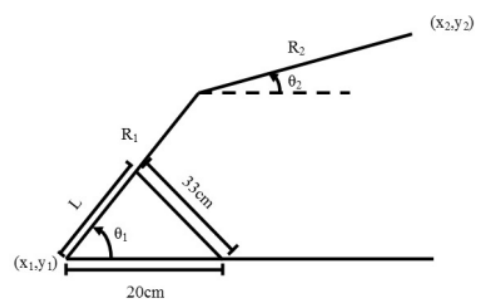

Figure A.3 C++ Programming Small Problem

Given a starting point ( $\mathrm{x}_{S}, \mathrm{ys}_{\mathrm{S}}$ ), a radius (R), and an angle $(\theta)$, you can determine the end point $\left(\mathrm{x}_{\mathrm{E}}, \mathrm{y}_{\mathrm{E}}\right)$

CEEA18; Paper 45

University of British Columbia, June 3-6, 2018 Page 10 of 10 a) Write a function that accepts a starting $\mathrm{x}$ value ( $\mathrm{x}_{\mathrm{S}}$ ), a radius $(\mathrm{R})$, and an angle $(\theta)$ and returns $\mathrm{X}_{\mathrm{E}}$.

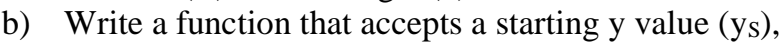
a radius $(\mathrm{R})$, and an angle $(\theta)$, and returns $\mathrm{y}_{\mathrm{E}}$.

c) Write a main that for all valid values of $L, R_{1}$, and $\mathrm{R}_{2}$, and $\theta_{2}$, calculates $\left(\mathrm{x}_{2}, \mathrm{y}_{2}\right)$.

Output the values for $L, R_{1}, R_{2}$, and $\theta$, if the resulting $\left(\mathrm{x}_{2}, \mathrm{y}_{2}\right)$ falls within a useful range

\section{Engineering Graphics Small Problem}

Your next task will be to create your assembly in AutoCAD. This will enable you to confirm that your design works, as well as factor in non-zero thicknesses/widths for your linkages and actuators.

1. Measure from a fixed base where your manipulator would need to be to reach the slots on the wall

2. Develop a free hand sketch of the different linkages you could use to hit the target locations

3. With the AutoCAD blocks, assemble your design with a 2D layout. You may also need to create some additional geometry to support your layout.

In your drawings, clearly specify the mounting locations for the actuators and show both start and end positions of the end effector.

\section{Main Design Problem}
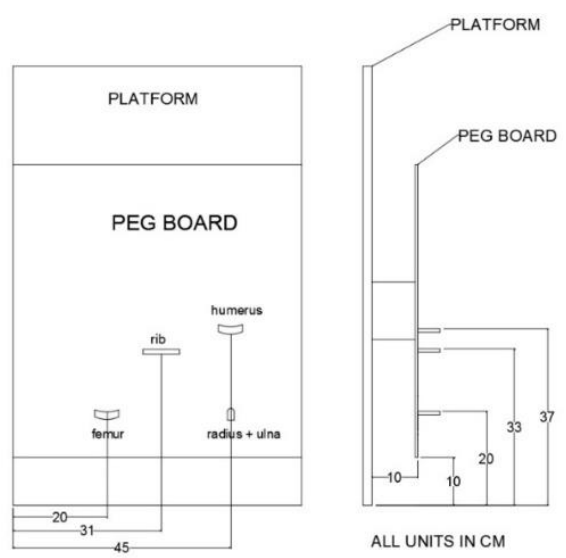

ALL UNITS IN CM

Figure A.4 Final demonstration board with dimensions

Your challenge is to design, build and operate a robotic manipulator. This robotic arm will need to pick up bones and insert them into a "patient". The bones must be placed in the correct location and in the correct orientation. To minimize discomfort, the bone should be placed with as little adjustment as possible.

The focus of your design will be to place the femur and the humerus in their correct locations. For those looking for a challenge, you can place the radius and rib. 